\title{
CARACTERIZAÇÃO FÍSICA DE SUBSTRATOS ORGÂNICOS PARA O ENRAIZAMENTO DE ESTACAS DE GOIABEIRA
}

\author{
Jussara Cristina Firmino da Costa $^{1 *}$, Rejane Maria Nunes Mendonça ${ }^{2}$, Leandro Firmino Fernandes ${ }^{2}$, \\ Flávio Pereira de Oliveira ${ }^{3}$, Djail Santos ${ }^{3}$
}

\begin{abstract}
RESUMO - O substrato é um fator determinante para obtenção de uma muda de qualidade, devendo este abranger aspectos econômicos, ecológicos, físicos e químicos, proporcionar sustentação durante o enraizamento das plantas e manter a base aquecida durante o enraizamento, enquanto promove boa umidade e permite aeração. O objetivo desse trabalho foi caracterizar fisicamente substratos orgânicos, de forma a subsidiar a escolha da mistura que poderá ser utilizada para o enraizamento de estacas de goiabeira. Os substratos avaliados foram à casca de arroz carbonizada (CAC), adquirida de uma empresa familiar, composto orgânico (CO) obtido pela compostagem de resíduos orgânicos (esterco bovino e materiais de limpeza do pomar: galhos, gramíneas, folhas e dentre outras). Cinco proporções foram formuladas: (S1 - 100\% CO; S2 - 25\% CAC + 75\% CO; S3 - 50\% $\mathrm{CAC}+50 \% \mathrm{CO} ; \mathrm{S} 4-75 \% \mathrm{CAC}+25 \% \mathrm{CO}$ e S5 - 100\% CAC), nas quais foi avaliada a densidade seca (Ds); Porosidade total (PT); Espaço de aeração (EA); Água facilmente disponível (AFD); Água tamponante (AT); Água disponível (AD) e Água remanescente (AR). O substrato S3 - (50\% casca de arroz carbonizada + 50\% composto orgânico) apresenta as características físicas adequadas para o processo rizogênico de goiabeiras.
\end{abstract}

Palavras-chave: Análise Física, Casca de Arroz Carbonizado, Composto Orgânico, Propagação.

\section{PHYSICAL CHARACTERIZATION OF ORGANIC SUBSTRATES FOR THE ROOTING OF GUAVA CUTTINGS}

\begin{abstract}
The substratum is a determinant factor to obtain a quality seedling, should this include aspects economic, ecological, physical and chemical, providing support during plants rooting and keep the base warm during rooting, while promote good humidity and allows aeration. The objective of this work was to characterize organic substrates physically, in order to subsidize the choice of the mixture that can be used for the rooting of guava cuttings. The substrates evaluated were the carbonized rice husk (CAC), acquired from a family business and the organic compound $(\mathrm{CO})$ obtained by composting organic waste (Orchard cleaning materials: twigs, grasses, leaves and among others) and cattle manure. Five propositions were formulated: (S1 - 100\% CO; S2 - 25\% CAC + 75\% CO;S3-50\% CAC + 50\% CO; S4 - 75\% CAC + 25\% CO e S5 - 100\% CAC), in which was measured the dry density (Ds); total porosity (PT); air space (EA); easily available water (AFD); buffering water $(A T)$; available water $(A D)$ and remaining water $(A R)$. The substrate $S 3-(50 \%$ carbonized rice husk $+50 \%$ organic compost) presents the physical characteristics suitable for the rhizogenic process of guava trees.
\end{abstract}

Key words: Analysis Physics, Rice husk Charred, Organic Compound, Propagation.eed.

\footnotetext{
${ }^{1}$ Doutoranda em Fitotecnia pela Universidade Federal de Viçosa, Viçosa-MG, 36570-900, Brasil. E-mail: jussara.costa@ ufv.br;

${ }^{2}$ Programa de Pós-Graduação em Agronomia, Departamento de Fitotecnia e Ciências Ambientais, Universidade Federal da Paraíba, Areia-PB, 58.397-000, Brasil;

${ }^{3}$ Programa de Pós-Graduação em Ciência do Solo, Departamento de Solos e Engenharia Rural, Universidade Federal da Paraíba, Areia-PB, 58.397-000, Brasil.
} 


\section{INTRODUÇÃO}

O crescimento populacional promove consequente aumento do consumo e geração de resíduos, muito deles aptos de reutilização ou reciclagem, promovendo benefícios ao meio ambiente, por reduzir a contaminação e favorecer a preservação dos recursos naturais. Neste contexto, o setor agrícola tem apresentado grande capacidade de aplicação desses materiais na forma de substrato, por ser uma importante fonte geradora de subprodutos ou resíduos, cujo reaproveitamento pode ocorrer no próprio segmento produtivo (Scivittaro et al., 2007; Campos, 2012).

Os resíduos utilizados como substrato para o enraizamento de estacas devem apresentar aspectos econômicos, ecológicos, físicos e químicos satisfatórios e serem livre de bactérias, fungos e outros patógenos para garantir a sanidade das plantas, baixo nível de salinidade e boa disponibilidade de nutrientes. Devem ainda proporcionar uma boa sustentação às estacas, mantendo a base aquecida enquanto promove umidade e aeração equilibradas, criando um ambiente com luminosidade reduzida, o que melhora tanto a porcentagem de enraizamento como a qualidade das estacas, favorecendo uma maior conformação e distribuição das raízes (Farias et al., 2012; Pagliarin et al., Alves, 2012).

Diversos materiais podem ser utilizados como substratos para o cultivo de espécies vegetais, mas é difícil encontrar um material que, isoladamente, atenda a todas as exigências da espécie a ser cultivada (Favalessa, 2011). Os materiais utilizados com maior frequência são a vermiculita, a areia, a casca de arroz carbonizada, moinha de carvão vegetal, turfa, serragem (Silva, 2012). No entanto, o custo, a distância das empresas e a dificuldade de aquisição limita a obtenção de certos produtos, principalmente para o pequeno viveirista, exigindo que este utilize materiais presentes na região de produção, facilitando o acesso e minimizando os custos (Steffen et al., 2010; Fermino et al., 2012).

A casca de arroz carbonizada e o composto orgânico são alternativas promissoras por apresentarem menor custo e maior facilidade de aquisição. A casca de arroz apresenta baixa densidade, lenta biodegradação, porosidade e drenagem, o que permite que as estacas mantenham a temperatura e a umidade adequadas, favorecendo o processo rizogênico (Saidelles et al., 2009). O composto orgânico pode ser obtido através da compostagem de resíduos da propriedade, como de podas, gramíneas e esterco bovino, além de ser uma ótima alternativa para equilibrar as características físicas da casca de arroz carbonizada, tal como a ancoragem (Saidelles et al., 2009).

Contudo, na avaliação da qualidade de um substrato não basta conhecer as propriedades gerais de seus principais componentes, é necessário determiná-las para cada ingrediente ou mistura em particular (Fermino, 2012). Pois, segundo Schmitz et al. (2002), materiais com elevada densidade, como é o caso da areia e do solo, quando utilizados de forma isolada, ou em grandes proporções dentro da mistura, tornam-se inconvenientes pelo peso excessivo, o que dificulta a manipulação das plantas nos recipientes, assim como a aeração e a drenagem.

Diante da necessidade do reaproveitamento de materiais disponíveis na região, como alternativa para melhorar o índice de enraizamento de estacas e baratear os custos de produção de uma boa muda, objetivouse caracterizar fisicamente substratos orgânicos, de forma a subsidiar a escolha da mistura que poderá ser utilizada para o enraizamento de estacas de goiabeira.

\section{MATERIAL E MÉTODOS}

Os substratos utilizados foram resultantes da mistura de materiais orgânicos, sendo a casca de arroz carbonizada (CAC), adquirida de uma empresa familiar e o composto orgânico (CO) obtido pela compostagem de resíduos orgânicos (materiais de limpeza do pomar: galhos, gramíneas, folhas e esterco bovino) no Viveiro de Fruticultura do Departamento de Fitotecnia e Ciências Ambientais, do Centro de Ciências Agrarias, da Universidade Federal da Paraíba (DFCA/CCA/UFPB). Para as avaliações, os substratos foram formulados conforme descrição na Tabela 1.

Tabela 1 - Substratos orgânicos a base de casca de arroz carbonizada (CAC) e de composto orgânico (CO) na forma pura e em mistura com diferentes proporções. Areia, PB, 2015

\begin{tabular}{cc}
\hline Substrato & Formulação \\
\hline S1 & $(100 \% \mathrm{CO})$ \\
S2 & $(25 \% \mathrm{CAC}+75 \% \mathrm{CO})$ \\
S3 & $(50 \% \mathrm{CAC}+50 \% \mathrm{CO})$ \\
S4 & $(75 \% \mathrm{CAC}+25 \% \mathrm{CO})$ \\
S5 & $(100 \% \mathrm{CAC})$ \\
\hline
\end{tabular}


A análise física dos substratos foi realizada no Laboratório de Física do Solo do Departamento de Solos e Engenharia Rural (DSER/CCA/UFPB), realizando-se triplicata de cada amostra. As variáveis analisadas foram:

- Densidade dos substratos (Ds) - utilizou-se o método empregado por Hoffman (1970). Para o cálculo da Ds, foi determinado o teor da matéria seca, através de secagem em estufa a $105^{\circ} \mathrm{C}$ até a estabilização do peso das amostras.

- Porosidade total, espaço de aeração e disponibilidade de água - realizada através de unidade de sucção, aplicando as tensões de $0,10,50$ e $100 \mathrm{hPa}$, conforme De Boodt \& Verdonck (1972). As curvas de retenção são efetuadas com os valores de umidade volumétrica (UV) obtidos através dos percentuais de água retida em cada tensão.

De posse desses dados, foram determinadas as seguintes variáveis:

- Porosidade Total (PT) - Corresponde á umidade volumétrica (UV) obtida entre a diferença nas amostras saturadas $(0 \mathrm{hPa})$ e após a secagem em estufa.

- Espaço de aeração (EA) - É a diferença obtida entre a porosidade total e a umidade volumétrica na tensão de $10 \mathrm{hPa}$.

- Água Facilmente disponível (AFD) - Corresponde a umidade volumétrica (UV) encontrada entre os pontos 10 e $50 \mathrm{hPa}$.

- Água tamponante (AT) - É a umidade volumétrica (UV) liberada entre 50 e $100 \mathrm{hPa}$.

- Água disponível (AD) - Volume de água liberado entre 10 e $100 \mathrm{hPa}$.

- Água remanescente (AR) - Volume de água que permanece na amostra após ser submetida à tensão de $100 \mathrm{hPa}$.

O delineamento experimental foi inteiramente casualizado com cinco tratamentos sendo utilizados dois materiais (composto orgânico e casca de arroz carbonizado), com três repetições cada. Os dados foram submetidos às análises de variância e regressão, utilizando o teste $\mathrm{F}(\mathrm{P} \leq 0,10)$ para se verificar o efeito dos tratamentos e o ajuste aos modelos de regressão testados.

\section{RESULTADOS E DISCUSSÃO}

A Figura 1 evidencia decréscimo na densidade dos substratos, com a elevação da proporção de casca de arroz carbonizada na mistura. Os substratos S1 (100\% $\mathrm{CO})$ e S2 (25\% CAC + 75\% CO) apresentaram $0,72 \mathrm{e}$ $0,61 \mathrm{~g} \mathrm{~cm}^{-3} \mathrm{de}$ densidade seca, respectivamente. Os valores de referência para densidade seca (Ds) recomendados por Conover (1967) estão entre 0,35 a $0,50 \mathrm{~g} \mathrm{~cm}^{-3}$ e entre 0,40 a $0,50 \mathrm{~g} \mathrm{~cm}^{-3}$ indicados por Bunt (1973). Portanto, os valores apresentados pelos substratos $\mathrm{S} 1$ e S2 podem dificultar a manipulação das plantas, podendo causar restrição ao crescimento das raízes. Em contrapartida, verifica-se que com o aumento da proporção da casca de arroz carbonizado e a diminuição do composto orgânico na composição dos substratos, os valores de Ds diminuem, com destaque para o uso do S4 (75\% CAC + 25\% CO) e S5 (100\% CAC) com os valores de 0,31 e $0,13 \mathrm{~g} \mathrm{~cm}^{-3}$, respectivamente. Altos valores de densidade são problemáticos e a baixa densidade pode promover problemas na fixação das plantas e o tombamento, dificultando o processo rizogênico. Deste modo, o substrato S3 (50\% CAC + 50\% CO) apresenta densidade compatível com os valores indicados pelos autores supracitados.

A densidade tem papel fundamental na escolha de um bom substrato, por presumir sobre outros atributos como porosidade, água disponível e espaço de aeração, uma vez que o aumento da variável densidade reduz a porosidade e modifica a relação entre substrato e estaca, propiciando o aumento da ocorrência de restrição ao crescimento das raízes (Ferraz, 2005; Ferreira, 2010). Baixas densidades permitem a utilização de materiais mais densos como condicionadores, demonstrando serem favoráveis quando utilizados para o enraizamento em tubetes (Schmitz et al., 2002).

Lang \& Botrel (2008) obtiveram maior produtividade em mudas de Eucalyptus grandis com a adição de 50\% de casca de arroz carbonizada no substrato comercial a base de casca de pinus em tubetes, por promover um maior contato entre o material vegetal e o substrato, reduzindo a perda de água por evaporação, aumentando a formação de raízes, permitindo que estas se desenvolvam de modo eficiente no substrato.

A porosidade total foi elevada com a adição de Casca de arroz carbonizada, até o ponto máximo de $88,18 \%$ com adição de $32,33 \%$ de CAC, decrescendo posteriormente. O substrato $\mathrm{S} 2(25 \% \mathrm{CAC}+75 \% \mathrm{CO})$ obteve valor de 
porosidade total (PT) aproximado do valor referência, 85\%, conforme DeBoodt \& Verdonck (1972), o que prediz uma melhor aeração, infiltração de água e drenagem, enquanto o S5 (100\% CAC) expôs um valor abaixo do recomendado, próximo de $30 \%$, o que é característico de materiais com baixa densidade (Figura 2).

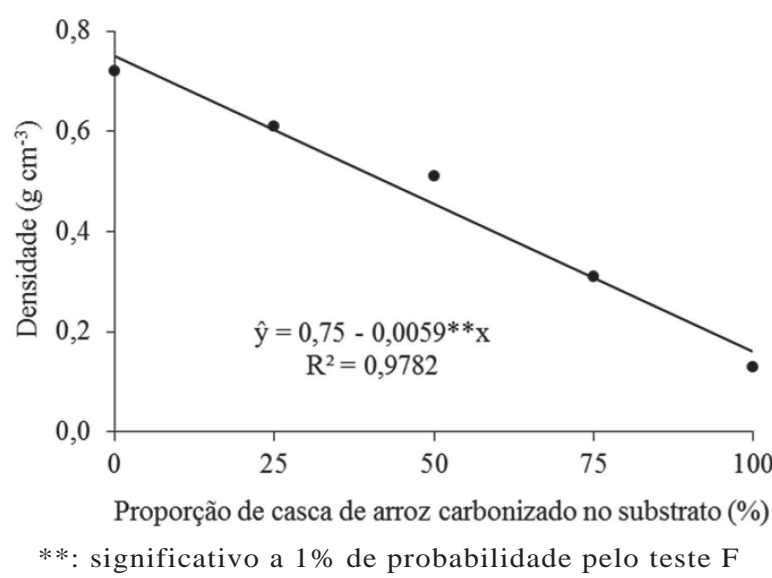

Figura 1 - Densidade seca de substratos preparados com composto orgânico $(\mathrm{CO})$ e casca de arroz carbonizado (CAC), com as seguintes formulações $(0$ corresponde a S1 - 100\% CO; $\mathrm{S} 2-25 \% \mathrm{CAC}+75 \% \mathrm{CO} ; \mathrm{S} 3-50 \% \mathrm{CAC}$ $+50 \% \mathrm{CO} ; \mathrm{S} 4-75 \% \mathrm{CAC}+25 \% \mathrm{CO}$ e S 5 - $100 \%$ CAC) Areia-PB.

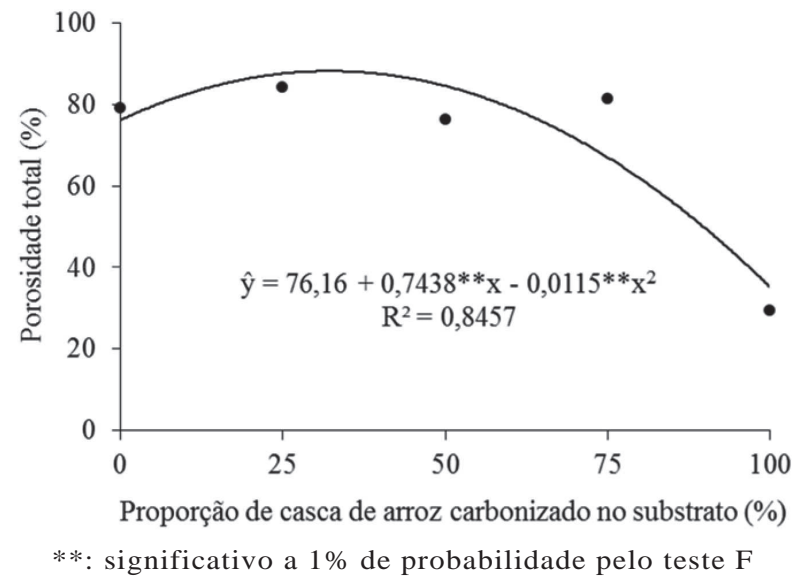

Figura 2 - Porosidade total (PT) de substratos preparados com composto orgânico (CO) e casca de arroz carbonizado (CAC), com as seguintes formulações ( 0 corresponde a $\mathrm{S} 1-100 \% \mathrm{CO}$; $\mathrm{S} 2-25 \% \mathrm{CAC}+75 \% \mathrm{CO} ; \mathrm{S} 3-50 \% \mathrm{CAC}+$ $50 \% \mathrm{CO} ; \mathrm{S} 4-75 \% \mathrm{CAC}+25 \% \mathrm{CO}$ e $\mathrm{S} 5-100 \%$ CAC) Areia-PB.
Materiais com baixa porosidade podem demonstrar problemas de trocas gasosas das raízes, movimentação de água e drenagem, influindo negativamente sobre o desenvolvimento das raízes e das plantas, ao contrário de misturas com porosidade mais elevada, podem ser vantajosas para a aeração radicular, mas podem resultar em baixa retenção de água, gerando deficiência hídrica, uma vez que os poros de menor tamanho são os responsáveis pela função de retenção de água (Zorzeto, 2011).

A determinação da porosidade total não faz distinção entre macro e microporos, o que dificulta a escolha do material a ser utilizado; desta forma, pode ser classificado como um parâmetro pouco informativo, quando avaliado isoladamente, por não especificar o tamanho dos poros, de maneira que o mesmo espaço poroso total pode ser ocupado por diferentes volumes de ar e água, e esse resultado é indicado pelo espaço de aeração e disponibilidade de água, respectivamente; pois a água retida no substrato está diretamente correlacionada com a distribuição dos poros por tamanho. Desta forma, a compactação do substrato reflete decréscimo da porosidade total, com destaque para os substratos com partículas menores e com maior desuniformidade do tamanho das partículas (Scivittaro et al., 2007; Pagliarin \& Castilho \& Alves, 2012), se fazendo necessário o uso de outras análises para uma melhor avaliação desse material.

Para o espaço de aeração (Figura 3), verifica-se crescimento ascendente, com o aumento da casca de arroz carbonizada no substrato. O substrato S1 (100\% $\mathrm{CO}$ ) apresenta espaço de aeração (EA) dentro do valor de referência (20 e 30\%.), conforme DeBoodt e Verdonck (1972). Nas demais formulações, o EA foi superior ao recomendado. O substrato S5 (100\% CAC) apresenta percentual de $94,8 \%$, valor próximo ao encontrado por Zorzeto (2011), que avaliando rendimento de morangueiro em diversos substratos, constatou que a casca de arroz apresentou valores próximos de $90 \%$ de EA, inferindo que esta composição pode gerar condições de deficiência hídrica às plantas, especialmente no caso de irrigações pouco frequentes, enquanto baixos valores de EA, que podem causar falta de oxigênio para o desenvolvimento das raízes.

Ferraz et al. (2005) evidenciam que os substratos devem ser escolhidos a partir da necessidade das plantas e da disponibilidade de irrigação, devendo apresentar 


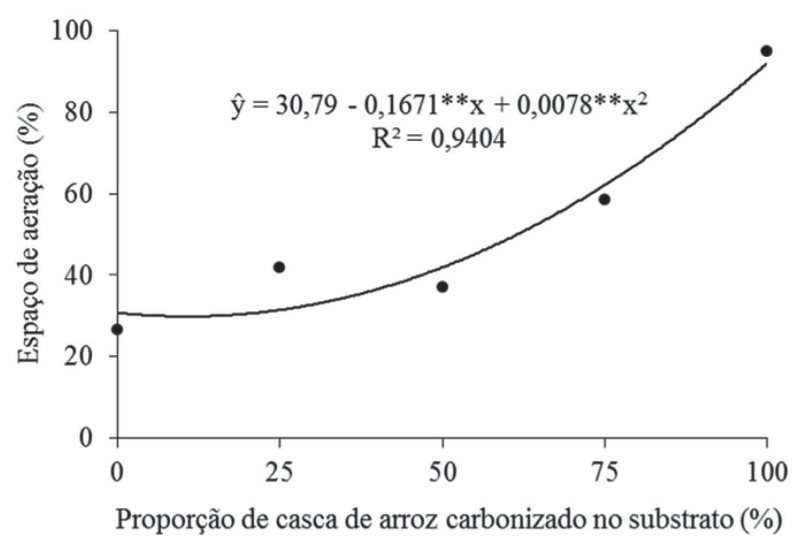

Figura 3 - Espaço de aeração de substratos preparados com composto orgânico $(\mathrm{CO})$ e casca de arroz carbonizado (CAC), com as seguintes formulações ( 0 corresponde a S1 - 100\% CO; $\mathrm{S} 2-25 \% \mathrm{CAC}+75 \% \mathrm{CO} ; \mathrm{S} 3-50 \% \mathrm{CAC}+$ $50 \% \mathrm{CO} ; \mathrm{S} 4-75 \% \mathrm{CAC}+25 \% \mathrm{CO}$ e S $5-100 \%$ CAC) Areia-PB.

algumas propriedades físicas próximas ao indicado para determinadas plantas e que estas variem em função da constituição, da granulometria e da compactação do substrato, o que apenas através da avaliação por meio de plantas nos diferentes substratos é possível inferir se as propriedades físicas desses substratos estão adequadas ou não para aquela cultura.

Para a água facilmente disponível (AFD) apresentou um modelo quadrático, com o ponto de mínima de $0,6 \%$ com a utilização de $37,23 \%$ de CAC. No substrato S4 os valores estavam compatíveis com os de referência, que de acordo com Cadahia (1998) são de $20 \%$ a $30 \%$, na composição S5 (100\% CAC) obteve-se um valor de $36,41 \%$ (Figura 4A). No entanto, a AFD é liberada sob baixas tensões, indicando que é rapidamente perdida, não se constituindo um reservatório de água para as plantas. Desta forma, quando no substrato há grande percentual de AFD, faz-se necessário o prolongamento nas regas, não sendo viável para o viveirista, por promover aumento nos gastos de produção de mudas.

Todos os substratos apresentaram valores para água tamponante (AT) abaixo do valor ideal de 5\% indicado por De Boodt \& Verdonck (1972) (Figura 4B). Substratos com valores iguais ou próximos ao recomendado proporcionam suprimento hídrico adequado para as plantas.
A água disponível (AD) apresentou o mesmo comportamento quadrático que a AFD assim como a mesma tendência para os substratos avaliados, onde o S5 (100\% CAC) foi o único que apresentou valor superior ao indicado, de $20 \%$ a $30 \%$ (Figura 4C) de acordo com De Boodt \& Verdonck (1972). Resultado justificado por ser a AD o volume de água retido sob tensões de 10 a $100 \mathrm{~cm}$ de coluna d'água, o que inclui as frações de AFD - 10 a $50 \mathrm{~cm}$ de coluna d'água e AT - 50 a 100 cm de coluna d'água. Mostrando que para estas composições de substratos, a AD é quase que integralmente constituída pela AFD, uma vez que praticamente não apresentou liberação de água entre as tensões de 50 a $100 \mathrm{hPa}$. Os baixos valores de AFD e AD nos substratos com maior proporção de composto orgânico evidenciam a contribuição da matéria orgânica, por possuir maior quantidade de microporos, em proporcionar maior adsorção de água.

Rota \& Pauletti (2008) trabalhando com proporções de turfa e casca de arroz carbonizada, concluíram que elevando acima de $50 \%$ a casca de arroz carbonizada nas proporções utilizadas, ocorre uma redução entre $14 \%$ e $15 \%$ da água disponível nos substratos. Assim como Schmitz (2002) que testando isoladamente e misturados à casca de arroz carbonizada, turfa vermelha escarificada, decomposto de casca de acácia e solo, constatou reduzido volume de água disponível de $9 \%$ a $26 \%$ para substratos isolados e de $9 \%$ a $17 \%$ para misturados. Isto indica que a disponibilidade de água pode ser um fator restritivo ao uso destes materiais de forma isolada, como substratos.

Zorzeto et al. (2014) trabalhando com seis substratos e dois métodos de caracterização, constataram que para a AFD o substrato mais crítico foi à casca de arroz, cujo valor nulo pode inibir o crescimento vegetal na falta de irrigações frequentes. Para AT apenas a fibra de coco granulada mostrouse adequada (5\%), garantindo à cultura certa quantidade de água para seu desenvolvimento mesmo em condições mais limitantes. Substratos que apresentam valores abaixo do recomendado tanto para AFD como para a AT apresentam limitações quanto ao suprimento adequado de água de fácil absorção para as plantas, indicando que, as regas devem ter durações mais curtas com intervalos de tempo menores (Schafer, 2004). 

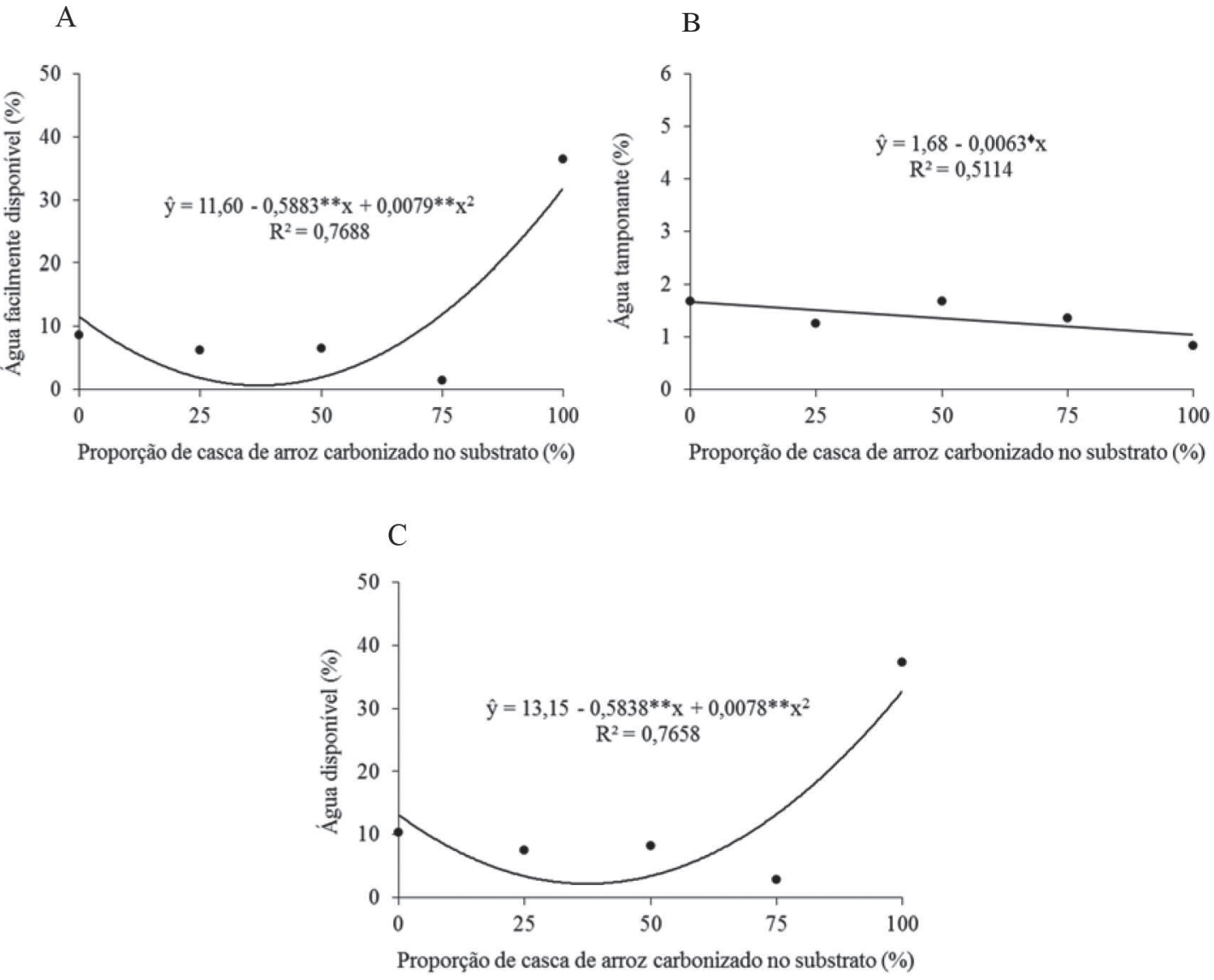

Figura 4 - Água facilmente disponível (A), Água tamponante (B) e Água disponível (C) de substratos preparados com composto orgânico (CO) e casca de arroz carbonizado (CAC), com as seguintes formulações (0 corresponde a S1 - 100\% CO; S2 - 25\% CAC + 75\% CO; S3 - 50\% CAC + 50\% CO; S4 - 75\% CAC $+25 \%$ CO e S5 - 100\% CAC) Areia-PB.

Os substratos apresentaram para a variável água remanescente (AR) comportamento linear decrescente (Figura 5) e as composições S3 $(50 \%$ CAC + 50\% CO) e S4 (75\% CAC+ $25 \% \mathrm{CO})$ atingiram valores de $31,09 \%$ e $19,95 \%$, respectivamente, que se aproximaram do valor de referência, entre 20 e 30\%, de acordo com De Boodt \& Verdonck (1972).

A AR representa a diferença entre a quantidade de água retida no substrato sob tensão de $100 \mathrm{~cm}$ de coluna d'água e a massa seca do substrato, estando essa presa nas partículas sólidas e não disponível para absorção das raízes, sendo mais frequente a ocorrência em substratos constituídos por alguns tipos de materiais orgânicos, de forma especial a turfa, tendo influência em algumas propriedades, tais como: condutividade elétrica, capacidade térmica e condutividade hidráulica, tendo em vista que a AR não está disponível as plantas (Scivittaro, 2007).

Os substratos S1, S2 e S5 não apresentaram disponibilidade condizente com os valores de referência, o que proporciona um possível estresse hídrico, sendo este prejudicado ainda mais pelo gasto de energia, por parte da planta, na busca de suprir a necessidade hídrica. Esse fato é relato por DeBoodt \& Verdonck (1972), tendo estes afirmando que a água deve estar disponível às plantas sob baixas tensões, evitando um possível estresse hídrico ou desvio da energia, a qual seria utilizada para o enraizamento e posterior crescimento da planta. Porém, deve-se considerar que, 


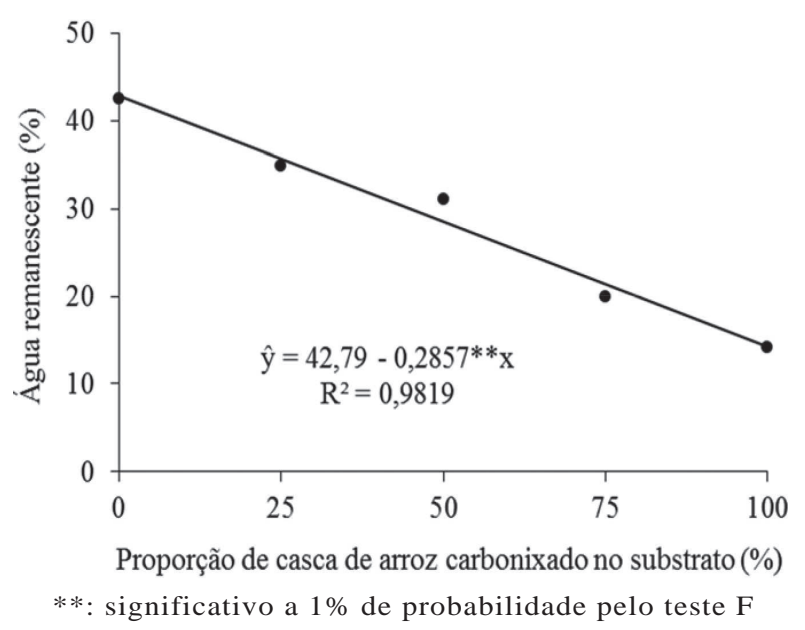

Figura 5 - Água remanescente de substratos preparados com composto orgânico $(\mathrm{CO})$ e casca de arroz carbonizado (CAC), com as seguintes formulações ( 0 corresponde a S $1-100 \%$ $\mathrm{CO} ; \mathrm{S} 2-25 \% \mathrm{CAC}+75 \% \mathrm{CO} ; \mathrm{S} 3-50 \% \mathrm{CAC}$ $+50 \% \mathrm{CO} ; \mathrm{S} 4-75 \% \mathrm{CAC}+25 \% \mathrm{CO}$ e S 5 - $100 \%$ CAC) Areia-PB.

a retenção de parte da água contida no substrato sob tensões elevadas, pode ser favorável às plantas, minimizando, ou mesmo evitando o excesso de umidade, quando se consideram substratos com elevada capacidade de retenção de água, sendo uma exceção, o período inicial da fase de enraizamento, em que a condição de umidade elevada é particularmente favorável (Scivittaro, 2007).

Devido ao alto valor de mudas formadas, o manejo de irrigação deve objetivar um fornecimento uniforme de ar e água às plantas, evitando alterações bruscas na dotação hídrica dos substratos durante o desenvolvimento da cultura, devendo-se utilizar um criterioso ajuste da quantidade de água aplicada, ajustando-se as taxas de vazão de água à capacidade de retenção do substrato, o que pode ser conhecida com base nas informações da caracterização física dos mesmos (Silva et al., 2011).

\section{CONCLUSÃO}

O substrato S3 (50\% casca de arroz carbonizada $+50 \%$ composto orgânico) apresenta as características físicas adequadas para ser utilizado no processo rizogênico de estacas de goiabeiras.

\section{REFERÊNCIAS BIBLIOGRÁFICAS}

BUNT, A.C. Some physical and chemical characteristics of loamless pot-plant substrates and their relation to plant growth. Plant and Soil, n.38, p.1957-1965, 1973.

CAMPOS, H.K.T. Renda e evolução da geração per capita de resíduos sólidos no Brasileira de Engenharia Sanitária e Ambiental, v.17, n.2, p.171-180, 2012.

CADAHIA, C. Fertirrigacion: cultivos hortícolas y ornamentales. Madrid: MundiPrensa, 1998. 475p.

CONOVER, C.A. Soil amendments for pot and field grown flowers. Florida Flower Grower, v.4, n.4, p.1-4, 1967.

DE BOODT, M.; VERDONCK, O. The physical properties of the substrates in horticulture. Acta horticulturae, v.26, p.37-44, 1972.FARIAS, W.C.; OLIVEIRA, L.L.P.; OLIVEIRA, T.A. et al. Caracterização física de substratos alternativos para produção de mudas. Revista

Agropecuária Científica no Semiárido, v.8, n.3, p.1-6, 2012.

FAVALESSA, M. Substratos renováveis e não renováveis na produção de mudas de Acacia mangium. Trabalho de conclusão de curso. Espirito Santo, 2011. 60f.

FERMINO, M.H.; KÄMPF, A.N. Densidade de substratos dependendo dos métodos de análise e níveis de umidade. Horticultura Brasileira, v.30, p.75-79, 2012.

FERRAZ, M.V.; CENTURION, J.F.; BEUTLER, A.N . et al. Caracterização física e química de alguns substratos comerciais. Acta Scientia Agronômica, v.27, n.2, p.209-214, 2005.

FERREIRA, R.R.M.; TAVARES FILHO, J.; FERREIRA, V.M. et al. Efeitos de sistemas de manejo de pastagens nas propriedades físicas do solo. Semina: Ciências Agrárias, v.31, n.4, p.913-932, 2010.

HOFFMANN, G. Binding methods for investigation of TKS and earth gartnerischen. Releases of VSLUFA, Heft, v.6, p.129-153, 1970. 
LANG, D.Z.; BOTREL, M.C.G. Desenvolvimento de mudas de Eucalyptus grandis em diferentes substratos. Revista Cultivando o Saber, v.1, p.107-117, 2008.

PAGLIARINI, M. K.; CASTILHO, R. M. M.; ALVES, M. C. et al. Caracterização físico-química de misturas de componentes de substrato com resíduo de celulose para fins de produção de mudas. Revista Brasileira de Agroecologia, v.7, n.2, p.160-169, 2012.

ROTA, L.D.; PAULETTI, G.F. Efeito da adição de casca de arroz em substrato comercial a base de turfa na produção de mudas de Viola tricolor L.

Revista Brasileira Agrociência, v.14, n.34, p.45-48, 2008.

SAIDELLES, F.L.F.; CALDEIRA, M.V.W.; SCHIRMER, W.N. et al. Casca de arroz carbonizada como substrato para produção de mudas de tamboril-da-mata e garapeira. Semina: Ciências Agrárias, v.30, sup. 1, p.1173-1186, 2009.

SCHAFER, G. Produção de porta-enxertos cítricos em recipientes e ambiente protegido no Rio Grande do Sul. Tese de doutorado (Fitotecnia). Porto Alegre, 2004. $144 \mathrm{p}$.

SCHMITZ, J.A.K.; SOUZA, P.V.D.; KAMPF, A.N. et al. Propriedades químicas e físicas de substratos de origem mineral e orgânica para o cultivo de mudas em recipientes. Ciência Rural, v.32, n.6, p.937-944, 2002.
SCIVITTARO, W.B.; SANTOS, K.F.; CASTILHOS, D.D. et al. Caracterização física de substratos elaborados a partir de resíduos agroindustriais. Pelotas: Embrapa Clima Temperado, 2007. 26p. (Embrapa Clima Temperado. Boletim de Pesquisa e Desenvolvimento, 58).

SILVA, E.A.; OLIVEIRA, G.C.; SILVA, B.M. et al. Avaliação da disponibilidade de água e ar em substratos agrícolas à base de turfa e casca de arroz carbonizada. Tecnologia e Ciência Agropecuária, v.5, n.4, p.19-23, 2011.

SILVA, R.B.G.; SIMÕES, D.; SILVA, M.R. et al. Qualidade de mudas clonais de Eucalyptus urophylla $x$ E. grandis em função do substrato. Revista Brasileira de Engenharia Agrícola e Ambiental, v.16, n.3, p.297-302, 2012.

STEFFEN, G.P.K.; ANTONIOLLI, Z.I.; STEFFEN, R.B. et al. Húmus de esterco bovino e casca de arroz carbonizada como substrato para a produção de mudas de boca-de-leão. Acta Zoologia mexicana, v.26, n.2, p.345-357, 2010.

ZORZETO, T.Q. Caracterização física e química de substratos para plantas e sua avaliação no rendimento do morangueiro (Fragaria $\div$ Ananassa duch.). Dissertação de mestrado (Agricultura Tropical e Subtropical). Campinas, 2011. 110f.

ZORZETO, T.Q.; DECHEN, S.C.F.; ABREU, M.F. et al. Caracterização física de substratos para plantas. Bragantia, v.73, n.3, p.300-311, 2014.

Recebido para publicação em 18/1/2017 e aprovado em 17/5/2017. 